\title{
ICU: ITS HISTORY, ITS DEVELOPMENT AND HENRI II OF FRANCE
}

\author{
TM Bird, Clinical Director; MB Smith, Lead Clinician, Critical Care, \\ Royal Lancaster Infirmary
}

\section{INTRODUCTION}

In May 2000, the Department of Health published a National Expert Group review of adult critical care services ${ }^{(1)}$. The government accepted that this should serve as the strategic framework document for development. The intention of this document is to break down the physical boundaries around critical care provision such that a spectrum of services would be developed to suit patient needs. This is reflected in the truly multi-disciplinary Critical Care Steering Group, which will develop the local strategy for critical care services around Morecambe Bay. The government allocated £145 million of new money to support initial developments ${ }^{(2)}$. This represented a step increase in annual spending on intensive care of approximately $20 \%{ }^{(3)}$. The political imperative was to increase the number of intensive care beds and reduce the number of ambulance transfers of very sick patients from December 2000. Initial reports from the Intensive Care Bed Information Service (ICBIS) suggest that this has been highly successful.

Intensive care has historically been defined as 'a service for patients with potentially recoverable conditions who can benefit from more detailed observation and invasive treatment than can safely be provided in general wards or high dependency areas'. High dependency care 'provides a level of care intermediate between that on a general ward and intensive care ${ }^{(4.5)}$. It is with these definitions in mind that we can trace the origins of ICU in Lancaster. Its development in Lancaster broadly parallels that seen throughout the UK over the last thirty years.

\section{THE EVOLUTION OF INTENSIVE CARE}

The popular belief that intensive care developed out of the poliomyelitis epidemic of the $1950 \mathrm{~s}$ is based on the development of longterm artificial ventilation. The anaesthetist's knowledge of airway management and the physiological effects of artificial ventilation meant that developments in intensive care were closely linked with those in anaesthesia. The modern ICU, however, can also trace its origins back to the establishment of post-operative recovery units $^{(6)}$, coronary care units ${ }^{(7)}$ and renal dialysis units through the 1960s and 70s. In North America, development tended to produce ICUs within a single hospital run by clinicians in many different specialities working in parallel. This resulted in an 'open ICU' model with patient care delivered by more than one group of doctors. The lack of control over admissions and resultant high costs has led to a change towards the 'closed ICU' model. In Europe, and especially the UK, there has been a convergence of skills of doctors primarily qualified in anaesthesia. The constraints imposed by central control on overall healthcare expenditure have favoured the 'closed ICU' model with a director of ICU administering agreed admission and discharge protocols.

\section{DEVELOPMENTS IN LANCASTER}

The driving force behind the development of intensive care in Lancaster was the arrival in 1972 from Oxford of Miles Rucklidge, consultant anaesthetist. In conjunction with Justin Kelly, consultant surgeon, he brought about the opening of the High Dependency Nursing Unit in 1976 which occupied three beds on Ward 1, in what is now Medical Unit 1. Several years and some interim moves later, the intensive care unit was opened in Ward 1 Annexe where the foundations of modern ICU practice were laid. No consultant sessions were allocated to ICU until 1985 and the unit was supported and administered by the on-call anaesthetic staff. From 1985 to 1995, two consultants shared the medical supervision of ICU (Mike Bird and Wally Park, later Mark Smith), since when there has been a considerable expansion in all aspects. There are now:

- 10 sessions per week of consultant time

- 5-10 sessions of $\mathrm{SHO} / \mathrm{SpR}$ anaesthesia time

- a training rotation established for surgical SHOs

- 41 whole time equivalent nurses (up from 16 in 1987)

- six ICU beds

- two HDU beds.

Table 1 documents some of the significant developments in Lancaster.

Some significant events in intensive care in Lancaster 1972-2001

1972 MA Rucklidge appointed. Barnet ventilator used on the general ward

1974 6-bed coronary care/medical ICU opened

1975 JF Kelly appointed

1976 3-bed high dependency nursing unit opened in Ward 1

1983 4-bed intensive care unit opened in Ward 1 Annexe. 4 Oxford ventilators

1985 invasive haemodynamic monitoring established

1988 patient monitors upgraded by £25k charitable donation

1989 audit of post-operative care indicates need for 4-bed ICU + 4-bed HDU

1992 interim ICU opened in old day-case/orthopaedic unit 3-bed ICU + 2-bed HDU

1993 continuous veno-veno haemofiltration established

1994 patient monitors upgraded by $£ 100 \mathrm{k}$ charitable donation

1995

1996

1999

2000 percutaneous tracheostomy established

Centenary Block ICU opened 3-bed ICU + 2-bed HDU

4th ICU bed funded

6th ICU bed funded. Charter Mark awarded

Table 1 Significant events in Lancaster 


\section{ACTIVITY IN THE YEAR 2000}

All admissions to ICU are logged both in the intensive care book and on computer. The latter is now part of the Intensive Care National Audit and Research Centre (ICNARC) database, the largest critical care audit in the world. We have been contributing for five years.

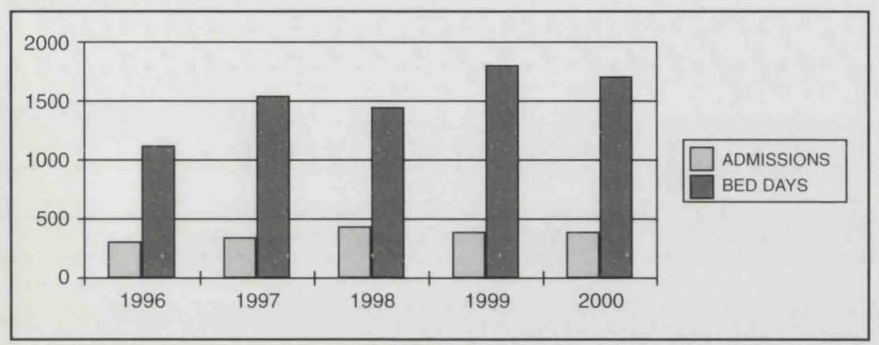

Admissions and bed days

\section{Patient admissions and bed days}

There has been a gradual increase in the number of patients we treat. It is related to increase in population, patient and medical expectations, changes in case mix and of course resources allowing us to treat. Long stay patients seriously affect our ability to admit other patients. The last two years has seen five patients staying longer than 70 days. There are in practice no facilities for longterm ventilated patients in the community.

\section{Length of stay}

The length of stay is determined not only by their disease but also by our ability to discharge to a general ward or other safe environment. If the wards are full, the patient remains on the unit and 'blocks' a bed. This has recently been a severe handicap.

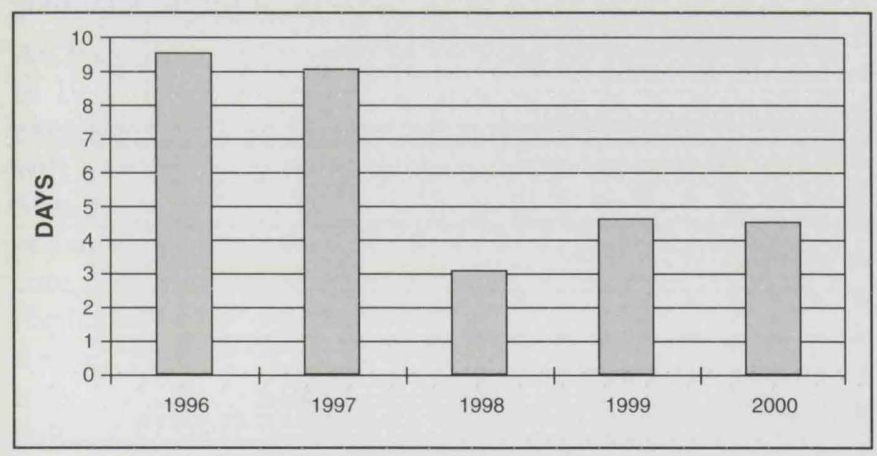

Length of stay

The length of stay graph clearly shows the influence of high dependency beds. There is a reduction in length of stay when HDU beds were opened. The steady increase since then is due to concentration of major surgery in Lancaster and an acute surgical bed shortage.

\section{Occupancy as a $\%$ of beds available}

A bed occupancy of $72 \%$ will allow for the management of $95 \%$ of local patients in their local (main trust) hospital. Occupancy is a factor of number of patients, disease process, local practice, intensive care resources and discharge bed availability. We have always had a bed occupancy above recommended levels resulting in increased resource allocation.

Bed occupancy is increasing. This is in the main due to an increasing workload, but is in part caused by an inability to discharge patients back to surgical and medical wards due to a bed shortage.

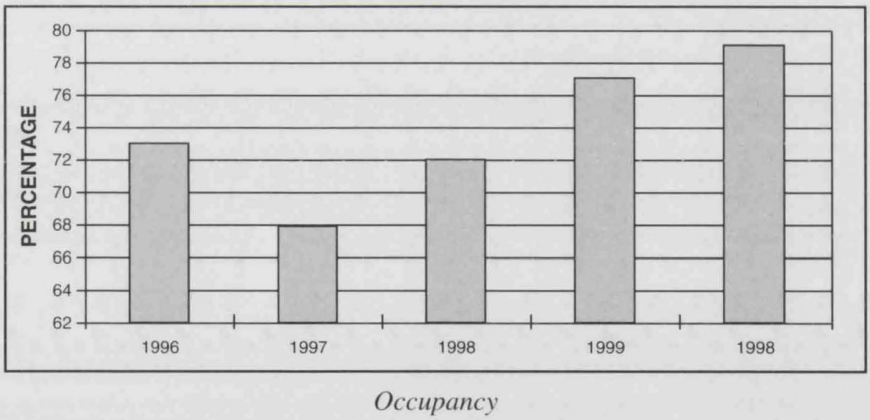

Admissions and bed days for the year 2000

We expect a seasonal variation in number of admissions and bed days. Winter causes an influx of medical patients with respiratory failure. It is at this time of year when staff sickness is highest and this causes difficulty in keeping beds open. Our staff numbers do not include an adequate allowance for sickness or study leave.

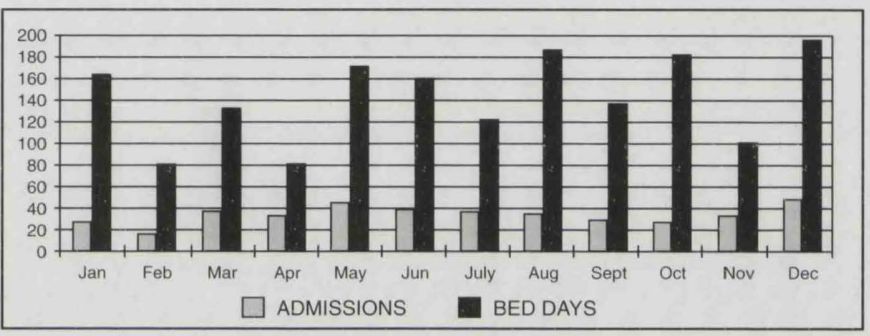

Admissions and Bed Days

The year 2000 was abnormal in that we had a second peak of activity in spring and early summer, the reason for which is unclear.

\section{Occupancy as a \% for the year}

We are working at a high bed occupancy.

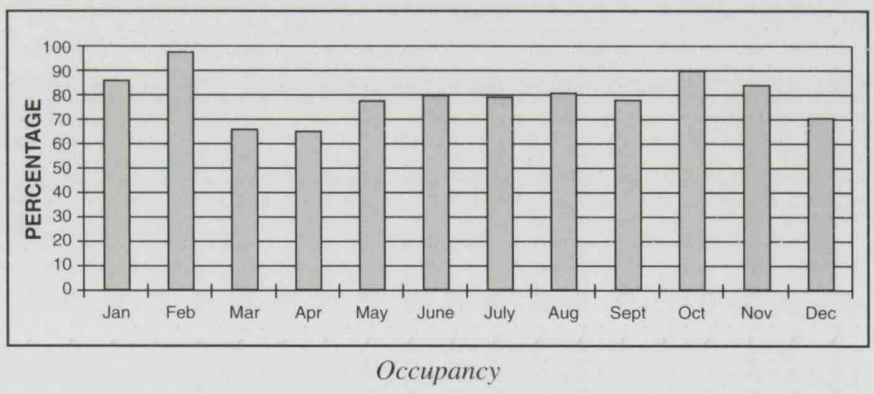

The December column indicates when two new intensive care beds were opened. The recommended level of occupancy to be able to manage $95 \%$ of local patients is $72 \%$. We operate above this level. The consequences of this are postponed operations, patient management in inappropriate areas and inter-hospital transfers.

\section{Transfers}

The major reason for the government's increase in spending on critical care was the alarming number of patients being transferred. This is monitored by Intensive Care Bed Information Service both in numbers, appropriateness and quality of transfer.

\section{Transfers, imports}

The years 1998 and 1999 saw a dramatic increase in the number of imports to Lancaster of critically ill patients. An increase in the number of ICU beds in the northwest in 1999 and 2000 saw a reduction in these transfers. There is seasonal variation with an increase in transfers in autumn, peaking in 
winter and spring. This is clearly due to climate-induced respiratory complications.

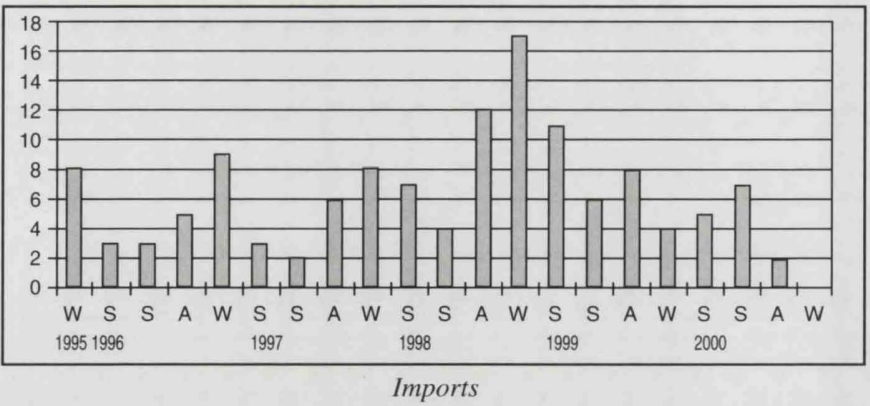

Transfers, exports

Transfers from Lancaster occur for two reasons. Firstly for expert or specialist care, eg neurosurgical for the head injuries, and secondly because there is no intensive care bed available locally.

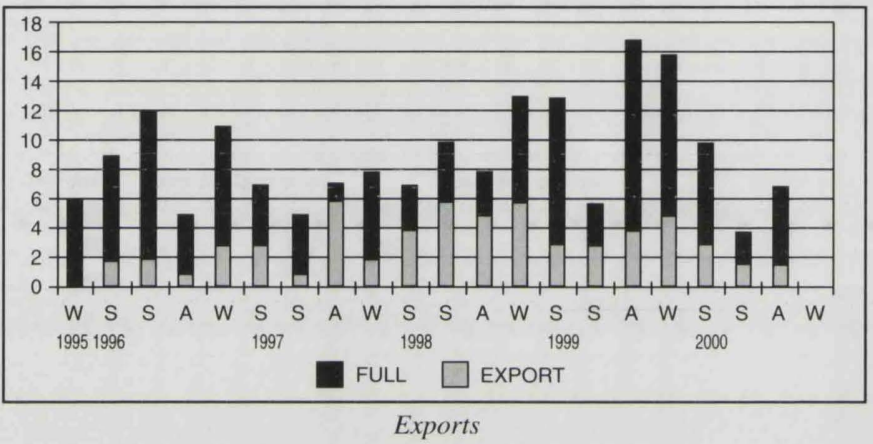

\section{OUTCOME FROM INTENSIVE CARE}

There is as yet no reliable assessment of outcome for critical care patients. The first known experiment in outcome prediction dates back to 1559 when Henri II, king of France, was gravely injured in a jousting contest. He had received a blow to the face and head from the splinters of a lance that ruptured his helmet. Henri's physicians were unable to determine how far the splinters had pierced his head. They obtained the stump of the splintered lance and jammed it with great force into the heads of four decapitated criminals who had been executed the previous day. The physicians then dissected each head to determine whether the splinters had entered the brain. This experiment proved to be as useless as our present day predictions. To complete the story, the brilliant anatomist Vesalius saw the king and announced the injury to be fatal. He was right. The king died 10 days later and post mortem showed severe brain injury with a subdural haemorrhage on the right side of the brain. The clinician's 'gut feeling' prevailed in this case.

The crucial outcome for patients in ICU is survival. It is, however, becoming increasingly clear that whilst survival may be a useful outcome measure for an ICU, for the individual patient there are other outcomes. On average $22 \%$ of patients will not survive ICU, a further $8 \%$ will die in hospital whilst another 7\% will die in the first six months post-discharge. Attention must now be focussed on the quality of survival (see D Wearing, p. 388).

We have a number of obligations to our patients besides striving to bring about survival. Professor Jennett ${ }^{(8)}$ summarised the potential for ICU to be harmful when it is:

- unnecessary, because routine care would have achieved the same result
- unsuccessful, because the patient is too ill to recover

- unsafe, because the risks of complications exceed the potential benefits

- unkind, because the subsequent quality of life is unacceptable

unwise, because of the diversion of limited resources.

Ruark and Raffin published some generally accepted principles for ICU in $1988^{(10)}$ including

- do no harm

- the primary objective is to preserve life, but this should be tempered by the need to alleviate suffering

- respect the patient's autonomy

- allocate resources fairly

- tell the truth.

In practice survival is determined by

- pre-existing health

- nature of the illness

- severity of the illness

- treatment given

response to treatment.

There have been many attempts to try to measure these variables as the basis for predictive models and outcome audit. The number of different approaches suggests that no method is perfect and given the heterogeneity of patients presenting to ICU this is hardly surprising. The most widelyused severity scoring systems are Apache $\mathrm{II}^{(10)}$ and Apache III ${ }^{(11)}$ although there are doubts about the benefits of the latter over the former. These systems attempt to control for case mix and allow meaningful comparisons of outcomes. They take into account Acute Psychological state, Age and Chronic Health Evaluation. Apache II is the most widelyused version in the UK and measures the following acute physiological indices, assessing the most aberrant recording during the first 24 hours of admission:

- rectal temperature

- mean blood pressure

- heart rate

- respiratory rate

- arterial partial pressure of oxygen

- arterial pH

- serum sodium

- serum potassium

- serum creatinine

- haematocrit

- white blood cell count

- Glasgow Coma Score

These indices are then weighted for the disease process and produce a score. The scores may be aggregated and used to assess the outcome of groups and patients and different ICUs. They are not intended for, or used in, the prediction of individual survival.

\section{OTHER MEASUREMENTS OF OUTCOME}

\section{TISS}

ICU activity may be measured and compared by assessing therapeutic interventions. The Therapeutic Intervention Scoring System (TISS) has been used both as a comparator between ICUs and as the basis of patient-episode costing. Points are allocated at time intervals to a large number of interventions, which may be in place ${ }^{(12)}$. The sum can be used as an assessment of the level of monitoring and care provided and can point towards costs. However, this method requires 


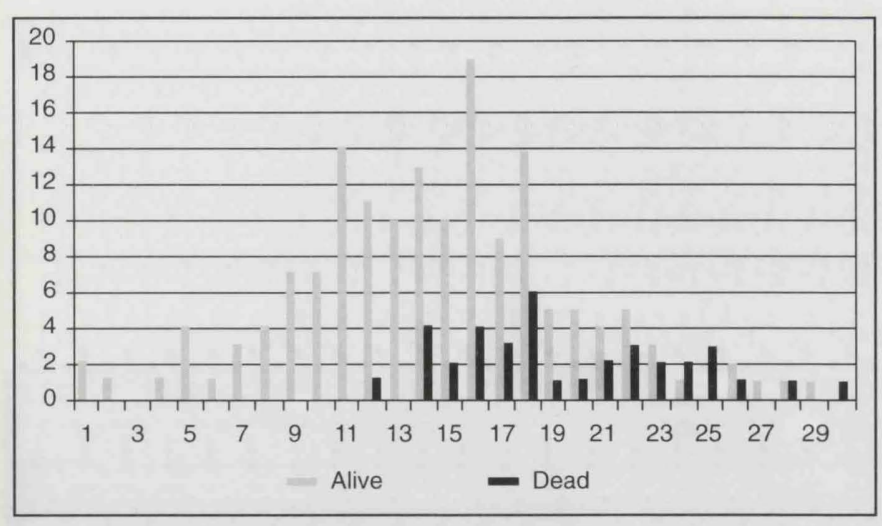

Apache and surgical patients

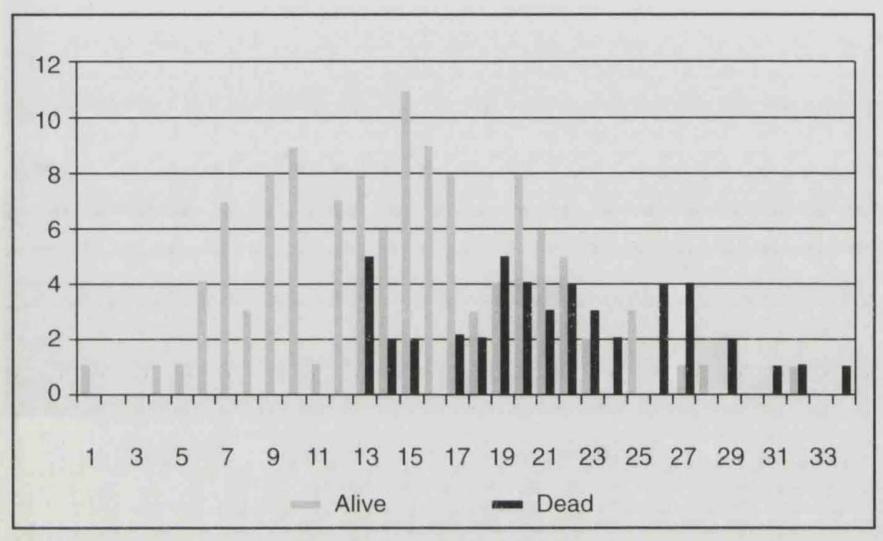

Apache for Medical Patients

considerable data input and great care in staff education to get consistent output and has not been universally adopted in the UK. Potentially this method could be used to link outcomes to resource allocation.

\section{ACP dataset}

In 1997, the NHS Executive initiated a central data collection exercise, the Augmented Care Period (ACP) Dataset ${ }^{(13)}$, which will serve the same purpose for critical care as the Contract Minimum Dataset does for other services. Its function is to provide standardised data on intensive and high dependency care activity to support contracting, internal management, national statistical analysis and policy development. The ACP dataset is relatively simple and is designed for integration into existing hospital data systems for simplicity of collection. Time will tell how useful this data will be. If nothing else it will help fill the black hole which previously existed in central government and NHS Executive knowledge of the critically ill.

\section{FUTURE DEVELOPMENTS}

The Morecambe Bay Acute Hospitals Critical Care Steering Group is charged with the development of the local strategy for critical care development. This is a multi-disciplinary, multi-skilled group under the chairmanship of an executive director of the trust. Critical care must be patient-focussed rather than system-focussed and the current physical and psychological barriers between intensive care and other services must be broken down. The aim will be to provide the right level of care to meet the patient's needs, wherever the patient might be.

With this in mind the developments are likely to focus on: - improved high dependency facilities across the trust
- setting up of educational and clinical support 'outreach' teams to develop skills on the general wards and provide a vital clinical link between wards and ICU/HDU

- closer links between all the disciplines that focus on patients: doctors, nurses, physiotherapists, pharmacists and any others who can help to improve the lot of the critically ill.

These developments do not always require additional resources but without additional funding there will be certainly be delay.

\section{SUMMARY}

Intensive care has progressed dramatically since its origins in the 1970s, to the point where it is now a recognised speciality. Resources have been increasing steadily but the benefits in patient outcome have been difficult to quantify.

There have been no randomised controlled trials of the intensive care process although it is noticeable that the Intensive Care Society is enabling the first multi-centre randomised controlled trial in the world for an ICU technique, the use of the Swann-Ganz or pulmonary artery catheter. This may point the way to evaluation of many other techniques, both inside and outside of our speciality. With such developments we can then truly start to link the allocation of resources more to clinical outcomes which can only be of benefit to individual patients and the National Health Service as a whole.

\section{REFERENCES}

1. Comprehensive Critical Care: a Review of Adult Critical Care Services Department of Health, May 2000

2. Modernising Critical Care Services Health Service Circular HSC 2000/017 Department of Health, May 2000

3. Edbrooke D. Intensive Care Society Newsletter, Spring 1998

4. Spiby J. Intensive Care in the United Kingdom: report of the King's Fund panel Anaesthesia 1989;44:428-431

5. The Intensive Care Service in the UK Intensive Care Society London HMSO 1990

6. Ruth HS, Hawgen FP, Grave DD. Anesthesia Study Commission: findings of eleven years' activity. J Am Med Assoc 1947;35:881-6

7. Day HW. An intensive coronary care area. Dis Chest $1963 ; 44: 423-5$

8. Jennett B. Inappropriate use of intensive care. Br Med J 1984;289:1709-11

9. Ruark JE, Raffin TA. Initiating and withdrawing life support. Principles and practice in adult medicine. NEJM 1988;318:25-30

10. Knaus WA, Draper EA, Wagner DP, Zimmerman JE. APACHE II: a severity of disease classification system. Crit Care Med 1985;13:818-29

11. Knaus WA, Wagner DP, Draper EA et al. The APACHE III prognostic system: risk prediction of hospital mortality for critically ill hospitalised adults. Chest 1991;100:1619-36

12. Cullen DJ, Civetta JM, Briggs BA, Ferrera LC Therapeutic Intervention Scoring System: a method for quantitative comparison of severity of illness in critically ill patients. Crit Care Med 1974;2:57-60

13. Intensive and High Dependency Care Data Collection NHS Executive, March 1997 